\title{
El edificio de Correos de Castellón
}

\author{
Encarna Ballester Mir
}

\section{Introducción}

En Castellón de la Plana, el edificio de Correos es de unas características muy singulares, diferente a todos los demás edificios de su entorno y, me atrevería a decir, de toda la ciudad, que llama la atención por su belleza y su construcción tan peculiar.

Está situado en un lugar muy céntrico de la ciudad, entre la plaza del rey D. Jaime, la calle Zaragoza y la plaza Tetuán.

Cuando estamos en su presencia, nos da una sensación de espledor y belleza, de unidad en sí mismo que, partiendo de una pesadez en la base, esta se va deluyendo a medida que alzamos la mirada debido a su gran cantidad de esbeltos vanos, al cambio de materiales a más ligeros y a la luminusidad que le da el juego de cerámicas de vistoso colorido, combinando con dibujos y grecas de ladrillo caravista.

\section{Contexto histórico en su construcción}

A nivel nacional, a finales del siglo xIX y principios del xx, los medios de comunicación adquieren una gran transformación: se mejoran todas las carreras desde Madrid a todas las capitales de provincia. La red electrotelegráfica llega a las capitales en 1863, los sellos de Correos se implantan en 1850 abaratando así el servicio. Influye también el avance del automóvil, el principio de la aviación, la construcción y ampliación de puertos de transporte marítimo y, sobre todo, la llegada, en 1855, del ferrocarril a España. En 1905 comienza el correo urgente, los giros y envíos contra reembolso en 1911 y los paquetes postales en 1916.

Debido a toda esta transformación, el servicio de Correos adquiere gran importancia y hace necesaria una regulación. Son importantes los reglamentos de 7 de junio de 1898 y la ley de 14 de junio de 1914, esta durante el gobierno de Maura en la que se establece que se construya en cada capital de provincia un edificio de Correos en el que se gestionen todos los servicios.

Castellón, a finales del siglo XIX y principios del Xx, experimenta un gran desarrollo. En el año 1833, Castellón es declarada capital de provincia; esto influye en un crecimiento demográfico continuo (de 15000 habitantes en 1850 pasó a 34000 en 1920) que responde a un gran desarrollo económico. La

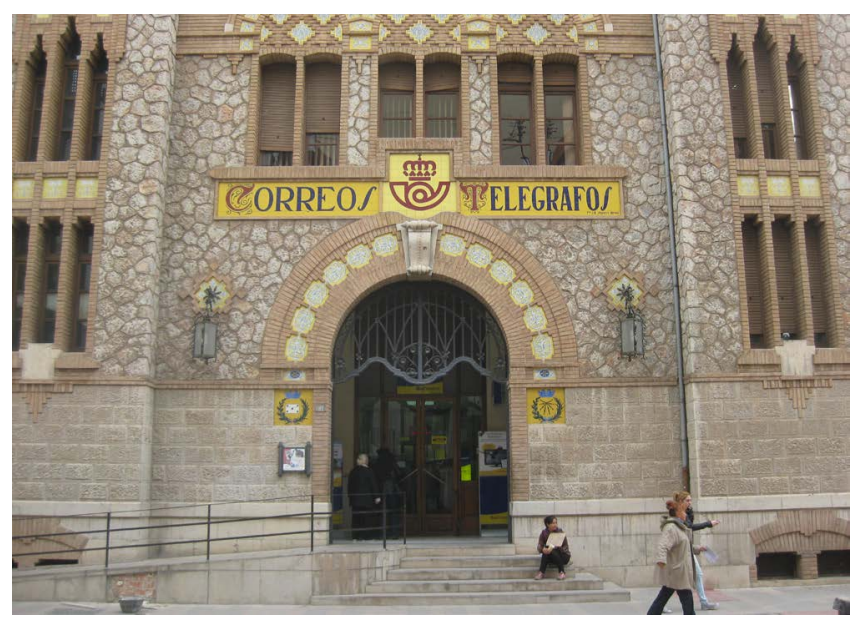

Figura 1. Fachada principal del edificio 
capital se establece como centro administrativo que tiene que atender a todas las demandas sociales, culturales y económicas, lo que hace necesaria una modernización urbanística; se mejoran las carreteas Madrid-Valencia, Barcelona y Zaragoza. Se construye el puerto de transporte marítimo, inaugurado en 1891.

En 1862 llega el ferrocarril a Castellón con lo que se hace posible el correo diario y que no se dependa del coche correo. Los castellonenses tienen en la memoria reciente el suceso del 14 de septiembre de 1850 en el que una gran tormenta ocasionó que las aguas torrenciales del barranco de Bellver arrastraran al mar el coche correo, pereciendo quince personas y cinco caballos.

\section{Proyecto}

El arquitecto D. Demetrio Ribes proyectó y planificó el edificio de Correos.

Nació en Valencia el 22 de diciembre de 1875, estudió en Barcelona y falleció el 3 de noviembre de 1921. Su arquitectura es de estilo modermista, en un principio centroeuropeo con un interés por las artes menores y el diseño; posteriormente se va decantando hacia una arquitectura españolicista y regionalista que tiende al eclesticismo y el racionalismo. Su proyecto del edificio de Correos no llegó a realizarlo al fallecer pocos años después.

El arquitecto castellonense D. Joaquin Dicenta Vilaplana estudió arquitectura en Barcelona y colaboró con $\mathrm{D}$. Demetrio Ribes en el proyecto de Correos y, al fallecer D. Demetrio, fue el quién siguió la construcción hasta su inauguración en 1932. Después se trasladó a Murcia, donde continuó con su obra arquitectónica.

El proyecto del edificio de Correos de Castellón salió a concurso el 28 de abril de 1916 y se le adjudicó a Ribes en el año 1917.

En el concurso se especificaba:

conseguir el carácter del edificio con arreglo a su destino y uso, por medio de bien trazadas fachadas, en las que campeen, a ser posible, los estilos históricos nacionales y sobre todo, los típicos en la localidad donde el edificio se construya de este modo se contribuirá al resurgimiemto ártistico de nuestra arquitectura y a la desaparición del exotismo.

El proyecto que presentó Ribes de carácter mudéjar tan ajeno a la ciudad responde al criterio del arquitecto de que dicho carácter es tópico del estilo en todo el territorio español. En él predomina el eclecticismo de la época a pesar de destacarse influencias casticistas y racionalistas.

Este estilo permite jugar con las texturas; estos cambios de material dan al edificio colorido y variaciones que adornan las paredes y, además, es más económico.

El edificio está concebido en su conjunto, no da más importancia a una fachada o a otra, aunque son todas similares en su temática constructiva, varían según su utilidad, que es diferente en cada una: atención al publico, funcionarios, paquetes y vivienda; con esto adquiere un sentido funcionalista que, unido a los elementos constructivos y decorativos, denota su tendencia racionalista.

El edificio es un rectángulo trapezoidal que no está adosado a ningún otro edificio, tiene las esquinas redondeadas y consta de tres plantas, cada una con funcionalidad determinada: en la primera, atención al público y reparto; en la segunda, funcionamiento $y$, en la tercera, vivienda.

\section{El edificio}

\section{Decoración}

La decoración viene dada por los mismos materiales que la componen, los constantes cambios de texturas y la intercalación de grecas, vanos, rosetones, etc., se juega con piedras de sillar, piedras irregulares y de distintos tamaños, con ladrillos caravista en distintas posiciones, creando salientes, frisos o medallones. Hay festones, triángulos, rombos, lineas dentadas y formas geométricas irregulares que crean un decorado muy atractivo. A esto hay que añadir la cerámica de vistoso colorido azul, blanco, con fondos amarillos, unas veces lisos, otras con motivos de animales o vegetales y otras lancelados, que destacan en gran manera del color terroso de los ladrillos, pero todos los adornos buscan siempre la simetría. En el panel cerá- 
mico con el nombre y el anagrama del edificio está la firma del artista: J. B. Segarra Bernat.

\section{Fachada frontal}

La fachada de la calle Zaragoza es la abierta al público, pero no por eso es más relevante que las demás. Consta, como todo el edificio, de cuatro cuerpos. El primero de grandes bloques de piedra sillar pulida con vanos a cada lado de la puerta de entrada. Le separa del siguiente cuerpo una linea de impostas del mismo material, de piedra menos pulida y de menor tamaño, separado del tercer cuerpo por una amposta de ladrillos caravista. El tercero es de piedras rústicas irregulares unidas por mampostería más oscura, y consta de dos zonas separadas por un friso corrido de cerámica con el nombre del edificio y su anagrama.

Debajo se encuentra el arco de la puerta de gran vistosidad que nace de una escalera de cinco peldaños. Del remate del friso de ladrillo caravista arrancan tres arcos de medio punto con vanos rebajados y, bajo el arco de descarga, se ve una decoración con cerámica.

En la parte superior de ladrillos caravista encontramos seis arcos más pequeños y, sobre ellos, una decoración de arcos fingidos y cerámica. La fachada está rematada por frisos de ladrillo y cerámica de los que parten siete pináculos neogóticos.

\section{Torreones}

Los torreones de ambos lados del frontal tienen la misma estructura. En el tercer cuerpo, encontramos dos conjuntos de tres vanos alargados muy esbeltos: los inferiores rematados por un estrechamiento y los superiores por un arco en cortina que recuerdan el estilo gaudiano. Están bordeados por un remate de ladrillo caravista y decorados con cerámica. En la parte superior, hay dos arcos de medio punto con un arco de descarga peraltado $y$ unos paneles de cerámica.

Se rematan con un alero muy pronunciado de influencia montañesa.

\section{Los ángulos}

Los cuatro ángulos redondeados del edificio es lo que da sensación de continuidad y una globaliza-

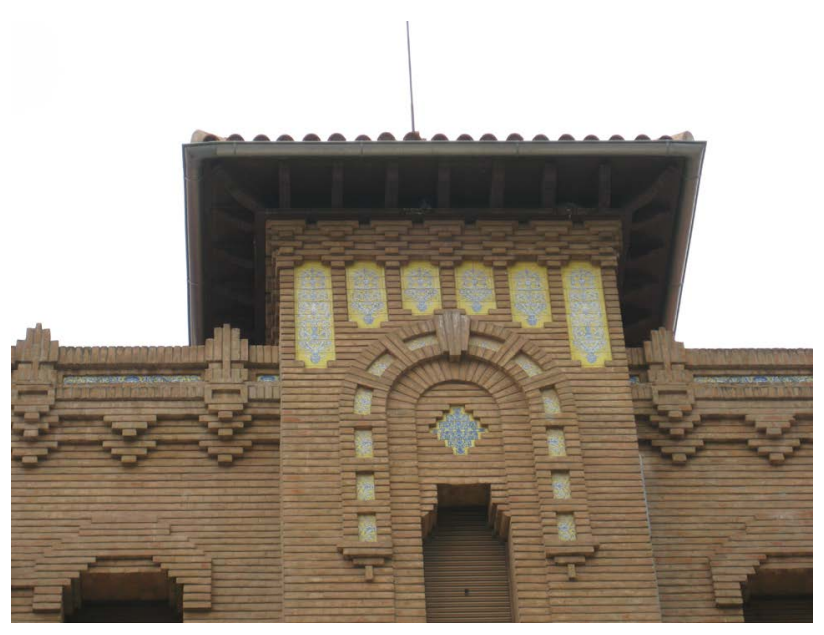

Figura 2. Detalle de un torreón

ción al edificio. A partir del primer cuerpo es todo de ladrillo caravista; los dos grupos de tres vados tienen la estructura similar a los de los torreones $y$, separadas por una moldura de ladrillos caravista, se ven otras tres ventanas. La esquina está rematada con un festoneado geométrico como el del frontal.

Las otras tres fachadas son de la misma estructura que la fachada abierta al público y de parecida decoración, pero no iguales: cada fachada tiene su característica propia dentro de la unidad.

\section{Interior}

El interior del edificio, esencialmente racional y funcional, delimita perfectamente el espacio para cada una de sus funciones: público, funcionarios y paquetes y clasificación.

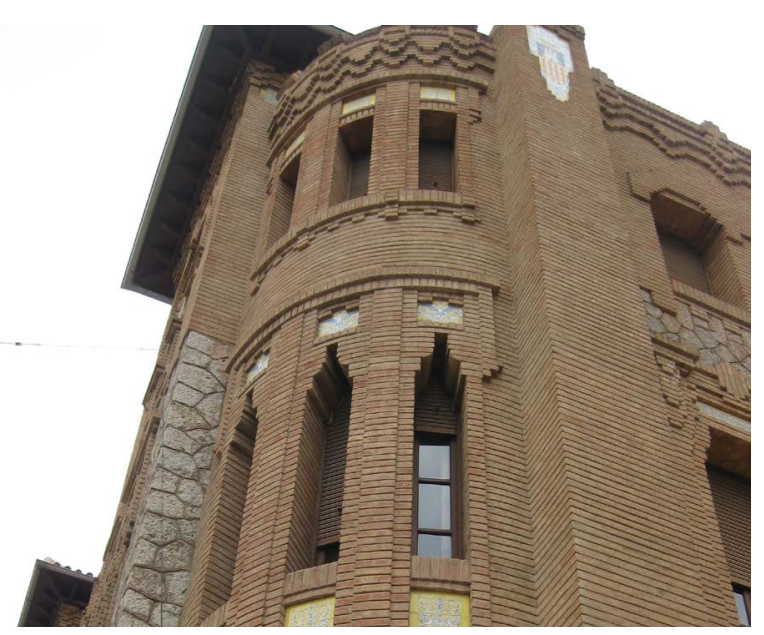

Figura 3. Detalle de un ángulo 


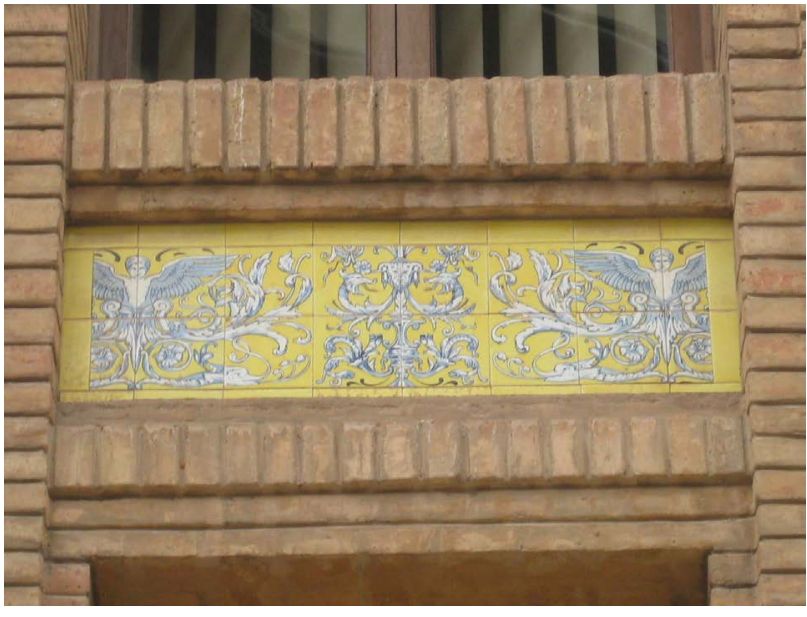

Figura 4. Detalle artístico de la fachada

La atención al público se realiza en un vestíbulo cuadrado donde están las ventanillas para los distintos servicios. Es un espacio cerrado, de madera $\mathrm{y}$ vidrio $\mathrm{y}$, en los ángulos, cuatro pilares unen el piso inferior con el superior, creando así una perspectiva de más altura que la real.
El vestíbulo se ilumina a través de una cubierta de hierro y vidrio decorado con un dibujo en forma de estrella de colores amarillos que deriva en octógonos y nerviaciones que llegan a lo alto de las pilastras.

En el piso superior, a través de unas vidrieras translúcidas, se iluminan las dependencias y estas están delimitadas en su parte superior por un friso de cerámica con dibujos y motivos valencianos de gran colorido. Esta técnica se llama trencádis (es la misma que Ribes utilizó en la estación del Norte de Valencia y en ella se nota la única influencia gaudiana, recogiendo la técnica costumbrista que se pedía para el proyecto.

Con la conjunción del hierro, la madera, el vidrio y la cerámica se denota la integración de las artes que siempre estuvo presente en la arquitectura de Ribes.

\section{Referencias}

Chust Calero, Manuel (dir.) (1992). Historia de Castellón. Levante de Castellón. Castellón.

Gimeno Michavilla, Vicente (1926). Del Castellón viejo. Caja de Ahorros y Monte de Piedad de Castellón. Pérez Rojas, J. (1990). Art Déco en España. Ediciones Cátedra. Madrid.

Traver, Tomás (1858). Antigüedades de Castellón de la Plana. Excmo. Ayuntamiento de Castellón. Castellón.

Fotografias: E. Ballester.

Consultas: oficina de Correos de Castellón y oficina de Correos de Valencia. 